\title{
Evaluation System Construction for Logistics Supply Chain of Cross-border E-commerce
}

\author{
Lianming Zhao \\ Department of business administration,Chongqing Business Vocational College, Chongqing \\ 401331, China \\ 849360877@qq.com
}

\begin{abstract}
Keywords: Cross-border E-commerce; logistic supply chain; evaluation system; low carbon; closed loop
\end{abstract}

\begin{abstract}
This paper establishes the optimization model of low-carbon closed-loop supply chain network with multiple objectives. Aiming at the model, a kind of improved genetic algorithm combined with $\varepsilon$ constraint method is raised to get the pareto optimal solution, which has been verified by algorithm case. The result of algorithm case shows that, the model can relatively reasonably solve the optimization problem of low-carbon closed-loop supply chain network with multiple objectives, and the used algorithm can efficiently get the pareto optimal solution. The article also discusses about the influence of utilization coefficient and partition coefficient of waste products to the range of pareto optimal solution, and analyze the reason why such influence is produced Finally, the article researches the variation range of optimal result when the product demand and product recycling demand of waste product in random. The article enriches the research content of low-carbon supply chain network and closed-loop supply chain network, is helpful for the enterprise to find the pareto optimal solution and control the range of pareto optimal solution by adjusting the coefficient, and also lay the foundation for establishing the low-carbon closed-loop supply chain network model with multiple products and periods.
\end{abstract}

\section{Introduction}

The greenhouse gases include the carbon dioxide, methane and nitrous oxide, etc., while the traffic tools are the main source of greenhouse gases. To lower the negative influence brought by the greenhouse gas and realize the sustainable development of population, environment and resource, the thought of low-carbon supply chain is raised. Low-carbon supply chain refers to that, blend the environmental protection thought in all logistics and supply chain links, to realize the green supply chain system with minimum carbon emission. With research on three-layer supply chain network under the multiple manufacturers, multiple distribution centers and multiple customers, Lv Pin puts forward the design model of supply chain network with consideration of carbon emission cost [1]. Ki-Hoon establishes the carbon footprint drawing of product, to be convenient for measuring and indentifying the carbon emission of automobile supply chain [2]. Under the premise with consideration of carbon dioxide emission, Samir Elhedhli et al build the convex function for the relation between the carbon emission and vehicle weight and solve with lagrangian method, with result showing that, the carbon emission has the great influence to the optimal result [3]. The above articles research the design issue of supply chain network under the carbon emission, while not discussing about the supply chain network under the recycling of waste product.

\section{Model proposal}

Taking the following closed-loop supply chain network, the network include the supply factory of raw material, factory, distribution center, recycling center, consumption area, maintenance center, disassembly center and decomposition center, etc. The operation process of low-carbon closed-loop supply chain network is as follows: The supply factory of raw material provides the raw material for 
the factory; the raw material forms the product after processing by the factory; the product is transported to the distribution center by the factory; after disposing by the distribution center, the raw material is transported to the consumption area; the recycling center carries the waste product back from the consumption area and disposes. There are 3 dispositions for the disposed waste products: The first one is the unrecyclable waste products, which are embedded and discarded after disposal; the second one is transported to the maintenance center for maintenance; the third one is transported to the disassembly center for disposal. There are 2 dispositions for the waste products transported to the maintenance center: The first one is the maintained products with recovered function, which are sold to the consumer directly by the maintenance center; for the second one, the products unable to be maintained and recovered are embedded and discarded after disposal. There 3 dispositions for the products transported to the disassembling center: The first one is the unrecyclable products by disassembling, which are embedded and discarded after disposal; the second one is the recyclable products by disassembling into components, with components transported to the factory as the raw materials; the third one is the recyclable products by disassembling into parts, with this part of waste products transported to the disassembly decomposition center. There are 2 dispositions for the waste products transported to the decomposition center: The first one is the products able to be reutilized by decomposition, with these parts transported to the factory as the raw material; the second one are the unrecyclable products by decomposition, which are embedded and discarded after disposal. All transportation are completed by three kinds of cars with transportation costs in different units. As shown in the Fig.1. The transportation cost has a positive correlation with the new or old degree of cars and transported quantity of products or waste products, namely, the newer the car is, the transportation cost is higher, and the more the products and waste products are transported, the transportation cost is higher. The carbon emission of each car has a negative correlation with the new or old degree of cars, and has a positive correlation with the transported quantity of products and waste products, namely, the newer the car is, the carbon emission is less, and the more the products and waste products are transported, the carbon emission is more. At the present, the problem is that, choose to operate one or several among the built-up supply factory of raw material, factory, distribution center, recycling center, maintenance center, disassembly center and decomposition center, and choose one or several among three kinds of cars with transportation cost in different units, to find the pareto optimal solution able to balance the carbon emission and total cost.

\section{Model assumption}

(1) The demands of every consumption area to the product and the recycling of waste product are determined.

(2) The supply factory of raw material, factory, distribution center, recycling center, consumption area, maintenance center, disassembly center and decomposition center only can be chosen in the built-up alternative sites.

(3) All transportation tasks are completed by three kinds of cars with cost in different units. The newer the car is, the transportation cost is higher, and the more the products and waste products are transported, the transportation cost is higher. The newer the car is, the emission carbon is less, and the more the products and waste products are transported, the carbon emission is more.

(4) The supply factory of raw material, factory, distribution center, recycling center, consumption area, maintenance center, disassembly center and decomposition center all have the limited production and processing capacity.

(5) Three kinds of new and old cars also have the limited transportation capacity.

(6) If the production supply of the distribution center to the consumption area is larger than the demand of the consumption area, then, the inventory carrying cost shall be considered, otherwise the losing opportunity cost shall be considered. If the recycling center does not recycle all waste products, then, the penalty cost shall be considered.

(7) If the production supply of the distribution center to the consumption area is larger or smaller than the demand of the consumption area, then, the punitive carbon emission shall be 
considered. If the recycling center does not recycle all waste products, then, the punitive carbon emission shall be also considered.

(8) The conversion coefficient between the raw material and product is definite. The recycling center, maintenance center, disassembly center and decomposition center shall respectively discard the unrecyclable waste products according the certain proportion, as the disposal of the waste unrecyclable product and the recyclable waste product all require the certain cost. The recycling center and disassembly center shall distribute the waste recyclable products according to the certain coefficient.

(9) Raw materials or components and parts produced by the supply factory of raw material, disassembly center and decomposition center are homogeneous and have no difference. The demand of the factory to the raw materials or components and parts must be satisfied by the joint supply from the supply factory of raw material, disassembly center and decomposition center, while it cannot be satisfied only by one of the supply factory of raw material, disassembly center and decomposition center.

\section{Meaning of parameters and variables in model}

$\mathrm{s}$ is the sth supply factory of raw material, and $\mathrm{S}$ is the assembly of raw material supply factories; $\mathrm{i}$ is the ith factory, and $\mathrm{I}$ is the assembly of factories; $\mathrm{l}$ is the lst distribution center, and $\mathrm{L}$ is the assembly of distribution center; $\mathrm{k}$ is the $\mathrm{kth}$ consumption area, and $\mathrm{K}$ is the assembly of consumption areas; $\mathrm{p}$ is the pth recycling center, and $\mathrm{P}$ is the assembly of recycling centers; $r$ is the rth maintenance center, and $\mathrm{R}$ is the assembly of maintenance centers; $\mathrm{d}$ is the dth disassembly center, and $\mathrm{D}$ is the assembly of the disassembly center; e is the eth decomposition center, and $\mathrm{E}$ is the assembly of decomposition center; $\mathrm{t}$ is the th kind of car, and $\mathrm{T}$ is the assembly of cars. vs, vi and vl respectively are the variable costs for the supply factory of raw material, factory and distribution center to produce the unit raw material or product ; vpr, vrr, vdr and ver respectively are the unit costs for the recycling center, maintenance center, disassembly center and decomposition center to dispose the recyclable products; vpw, vrw, vdw and vew respectively are the unit cost for the recycling center, maintenance center, disassembly center and decomposition center to dispose the unrecyclable products. fsit is the unit product transportation cost to transport the raw material from the sth supply factory of raw material to the ith factory with the tth kind of car; filt is the unit product transportation cost to transport the product to from the ith factory to the lth distribution center with tth kind of car; flkt is the unit product transportation cost to transport the product from the lth distribution center to the kth consumption area with the th kind of car; fkpt is the unit product transportation cost to transport the waste product from the kth consumption area to the pth recycling center with the th kind of car; fprt is the unit product transportation cost to transport the waste product from the pth recycling center to the rth maintenance center with the th kind of car; fpdt is the unit product transportation cost to transport the waste product from the pth recycling center to the dth disassembly center with the tth kind of car; fdet is the unit product transportation cost to transport the waste product from the dth disassembly center to the eth decomposition center with the th kind of car; fdit is the unit product transportation cost to transport the waste product from the dth disassembly center to the ith factory with the tth kind of car; feit is the unit product transportation cost to transport the waste product from the eth decomposition center to the ith factory with the tth kind of car. dk is the product demand of kth consumption area, and qk is the demand of kth consumption area to recycle the waste product. $w_{k}^{f}$ is the unit opportunity cost brought by the product short supply in the kth consumption area, and $w_{k}^{e}$ is the unit inventory cost brought by the product oversupply in the kth consumption area, while is the unit penalty cost for incomplete recycle of waste product in the kth consumption area. $c_{k}^{f}$ is the unit punitive carbon emission for the consumer purchasing substitute goods caused by the product short supply in the kth consumption area; is the unit punitive carbon emission for the resource waste caused by the product oversupply in the kth consumption area; $c_{k}$ is the unit punitive carbon emission for the discard at 
will of incompletely recovered waste product in the kth consumption area. $\theta p, \delta r$, $\alpha \mathrm{d}$ and $\beta \mathrm{e}$ respectively are the recycling coefficients of waste product in the recycling center, maintenance center, disassembly center and decomposition center; $\varepsilon p$ and $\eta d$ respectively are the distribution coefficients of the recycling center and disassembly center; is the raw material - product conversion coefficient of the factory. cs, ci, cl, cp, cr, cd and ce respectively are the maximum production or processing abilities of the supply factory of raw material, factory, distribution center, recycling center, maintenance center, disassembly center and decomposition center; cts, cti, ctl, ctp, ctr, ctd, cte, ctdi and ctei respectively are the maximum transportation abilities for each kind of car from the supply factory of raw material to the factory, from the factory to the distribution center, from the distribution center to the consumption area, from the consumption area to the recycling center, from the recycling center to the maintenance center, from the recycling center to the disassembly center, from the disassembly center to the decomposition center, from the disassembly center to the factory, and from the decomposition center to the factory.

Respectively are whether operate the sth supply factory of raw material, the ith factory, the lth distribution center, the pth recycling center, the rth maintenance center, the dth disassembly center and the eth decomposition center, with 1 representing operating and 0 representing not operating. xsit is the quantity of raw materials transported from the sth supply factory of raw material to the ith factory with the tth car; xilt is the product quantity transported from the ith factory to the lth distribution center with the tth car; xlkt is the product quantity transported from the lth distribution center to the kth consumption area with the tth car; xkpt is the quantity of waste products transported from the kth consumption area to the pth recycling center with the th car; xprt is the quantity of waste products transported from the pth recycling center to the rth maintenance center with the tth car; xpdt is the quantity of waste products transported from the pth recycling center to the dth disassembly center with the tth car; xdit is the component quantity transported from the dth disassembly center to the ith factory with the tth car; xdet is the quantity of waste products transported from the dth disassembly center to the eth decomposition center with the tth car; xeit is the quantity of parts and components transported from the eth decomposition center to the ith factory center with the tth car. ${ }^{x_{k}^{f}}$ is the product quantity of short supply in the kth consumption area, and $x_{k}^{e}$ is the product quantity of oversupply in the kth consumption area, while $x_{k}$ is the quantity of waste products not recycled in the kth consumption area.

In conclusion: In the Formula (1), Y is the cost of low-carbon closed-loop supply chain network; $\mathrm{Y} 1$ is the variable cost for the supply factory of raw material, factory and distribution center to transport, process and dispose the raw material or product; Y2 is the variable cost for the recycling center and maintenance center to transport, process and dispose the raw material or product; Y3 is the variable cost for the disassembly center and decomposition center to transport, process and dispose the waste product; Y4 is the transportation cost for the disassembly center and decomposition center to transport the parts and components to the factory; Y5 is the cost brought by the product short supply, product oversupply and incomplete recycle of waste product in the consumption area. In the Formula (2), C is the carbon emission of low-carbon closed-loop supply chain network; $\mathrm{C} 1$ is the carbon emission of forward supply chain network; C2 is the punitive carbon emission brought by the product short supply, product oversupply and incomplete recycle of waste product in the consumption area; C3 is the carbon emission of reverse supply chain network. The 11th formula shows that every consumption keeps balance in the product supply and demand; the 12th formula shows that every factory keeps balance in the product supply and demand; the 13th formula shows that every distribution center keeps balance in the product supply and demand; the 14th formula shows that every consumption keeps balance in the waste product supply and demand; the 15th formula shows that every recycling center keeps balance in the maintainable waste product supply and demand; the 16th formula shows that every recycling center keeps balance in the dismountable waste product supply and demand; the 17th formula shows that every disassembly center keeps balance in the dismountable waste product supply and demand; the 18th formula shows that every decomposition center keeps balance in the decomposable waste product supply and demand. The Formula (20) - (26) respectively represent the maximum processing or production 
capacity limit of the supply factory of raw material, factory, distribution center, recycling center, maintenance center, disassembly center and decomposition center. The Formula (27) - (35) respectively represent the maximum transportation capacity limit of each kind of car from the supply factory of raw material to the factory, from the factory to the distribution center, from the distribution center to the consumption area, from the consumption area to the recycling center, from the recycling center to the maintenance center, from the recycling center to the disassembly center, from the disassembly center to the decomposition center, from the disassembly center to the factory, and from the decomposition center to the factory. The Formula (36) represents that there only are two kinds of conditions of operating or not operating in the supply factory of raw material, factory, distribution center, recycling center, maintenance center, disassembly center and decomposition center. The Formula (37) represents that: all variables must be equal or greater than zero.

\section{Improved genetic algorithm for optimization of low-carbon closed-loop supply chain network}

The above model is a mixed integral linear programming model with multiple objectives and multiple constraints. Normally, it is hard to directly solve the model. As a kind of overall probabilistic search algorithm, without convexity, differentiability and other special requirements to the objective functions, the genetic algorithm can process the optimization problems with multiple objectives and multiple constraints. Fulya et al find the pareto optimal solution of the supply chain network under multiple objectives with the genetic algorithm [15]. Yeh solves the partner selection problems of green supply chain network with the genetic algorithm [16]. Therefore, aiming at the characteristic of the low-carbon closed-loop supply chain network model with multiple objectives, this paper puts forward a kind of improved genetic algorithm combined with the $\varepsilon$ constraint method, to get multiple groups of pareto optimal solutions, while the solution in the solution set shows that, there is no feasible solution which can improve other objectives without sacrifice other objectives. The concrete contents include the following 3 stages.

(1) Get the minimum carbon emission Cmin with the carbon emission as the single objective, and calculate the total cost $\mathrm{Y}$ at the time. The stage includes the following 4 steps: (1) Code chromosome and generate initial population. Every chromosome is in correspondence with one low-carbon closed-loop supply chain network, representing the chromosome with the integer set constituted by 0 and 1; 0 and 1 represents the operating condition of the supply factory of raw material, factory, distribution center, recycling center, maintenance center, disassembly center and decomposition center, with 1 representing operating and 0 representing not operating. The chromosome length is length(S)+length(I)+ length(L)+ length(P)+ length(R)+ length(D)+length(E), length(S), and the length(S) represents the number of operated supply factories of raw material, while meaning of another symbols are similar. Apply the crtbp order in the genetic algorithm toolbox of Shieffield University, create the random population of discrete values, and the population includes several chromosomes meeting the requirements. (2) Calculate objective function value of every individual in the population and evaluate. By utilizing the accurate algorithm of linear programming model in the matlab, the function value corresponding to every chromosome can be gotten. With function value of every individual (chromosome) as the evaluation standard of fitness, as well as the use linear ordering and selection pressure difference as 2, estimate the fitness, and order from small to large in accordance with the fitness, while the smaller the function value is, the fitness is higher, and the corresponding carbon emission is smaller. (3)Design the genetic operator. Choose the operator with wheel disc, choose the individual with large fitness for crossover and mutation in every generation of population, with the crossover in single-point crossover way and the mutation in discrete mutation way. According to the generation gap ratio, reserve the elites (individual with high fitness) in the last generation, and add them into the next generation to enable the individual number of next generation to be same as that of the last generation. (4)Judge whether it satisfy the condition to stop the operation; if it is not satisfied, then circulate the (2)-(3) until satisfying the condition to stop the operation.

(2) Get the minimum total cost Ymin with the total cost as the single objective, and calculate 
the carbon emission $C$ at the time. The calculation step is similar to that of the first stage.

The third stage is divided as two conditions of 3-1 and 3-2, and what obtained are the pareto optimal solutions.

(3-1) Select the Formula (1) as the objective function, add the constraint condition $C \in[$ Cmin -100, Cmin], and calculate the minimum total cost Ypareto under this constraint condition. The calculation step is similar to that of the first stage. Therefore, (Ypareto, Cmin) constitute a group of pareto optimal solution. According to the $\varepsilon$ constraint method with multiple objective planning, determine a suitable $\mathrm{z}$ value, to determine the group number of pareto optimal solution generated by the system; with the $\mathrm{bz}=(\mathrm{C}-\mathrm{Cmin}) / \mathrm{z}$ as the step length, respectively calculate the minimum total cost Ypareto when $\mathrm{C} \in[\mathrm{Cmin}-100+\mathrm{bz}, \quad \mathrm{Cmin}+\mathrm{bz}], \quad \mathrm{C} \in[\mathrm{Cmin}-100+2 \times b z$, $\mathrm{Cmin}+2 \times \mathrm{bz}] \ldots \mathrm{C} \in[\mathrm{Cmin}-100+\mathrm{z} \times \mathrm{bz}, \mathrm{Cmin}+\mathrm{z} \times \mathrm{bz}]$. And, $\mathrm{z}+1$ groups of pareto optimal solutions can be gotten.

(3-2) Select the Formula (2) as the objective function, add the constraint condition Ye[ Ymin -100 , Ymin], and calculate the minimum carbon emission Cpareto under this constraint condition. The calculation step is similar to that of the first stage. Therefore, (Ymin, Cpareto) constitute a group of pareto optimal solution. According to the $\varepsilon$ constraint method with multiple objective planning, determine a suitable $\mathrm{z}$ value, to determine the group number of pareto optimal solution generated by the system; with the $\mathrm{bz}=(\mathrm{Y}-\mathrm{Ymin}) / \mathrm{z}$ as the step length, respectively calculate the minimum carbon emission Cpareto when $\mathrm{Y} \in[\mathrm{Ymin}-100+\mathrm{bz}, \mathrm{Ymin}+\mathrm{bz}], \mathrm{Y} \in[\mathrm{Ymin}-100+2 \times b z$, $Y \min +2 \times b z] \ldots Y \in[Y \min -100+z \times b z, Y \min +z \times b z]$. And, $z+1$ groups of pareto optimal solutions can be gotten.

\section{Algorithm case}

Take 3 alternative supply factories of raw material, 3 alternative factories, 5 alternative distribution centers, 3 alternative recycling centers, 6 consumption areas, 2 maintenance centers, 2 disassembly centers and 2 decomposition centers into account. The unit transportation cost of old car is 108 yuan/part, and the unit transportation cost of medium new or old cars is 126 yuan/part, while the unit transportation cost of new car is 144 yuan/part. The unit carbon emission of old car is $1.5 \mathrm{~g} /$ part, and the unit carbon emission of medium new or old cars is $1.3 \mathrm{~g} /$ part, while the unit carbon emission of new car is $1 \mathrm{~g} /$ part. The product conversion coefficient of raw material is $\lambda=0.6$. The unit variable costs of various facilities are as shown in the Table 1 . Various coefficients are as shown in the Table 2. The unit cost and unit carbon emission in the product short supply, product oversupply and incomplete recycle of waste product are as shown in Table 3. The demands of consumption area to the product and to the recycle of waste product are as shown in Table 4 . The maximum production or processing capacities of various facilities are as shown in Table 5. The maximum transportation capacities of various cars under different conditions are as shown in Table 6.

\begin{tabular}{|c|c|c|c|c|c|c|c|c|c|c|}
\hline $\mathrm{v}_{\mathrm{S}}$ & $v_{i}$ & $\mathrm{v}_{\mathrm{l}}$ & $\mathrm{v}_{\mathrm{pr}}$ & $v_{p w}$ & $\mathrm{~V}_{\mathrm{dr}}$ & $\mathrm{v}_{\mathrm{dw}}$ & $\mathrm{V}_{\mathrm{rr}}$ & $\mathrm{V}_{\mathrm{rw}}$ & $\mathrm{V}_{\mathrm{er}}$ & $\mathrm{V}_{\mathrm{ew}}$ \\
\hline 1 & 1 & 1 & 1.2 & 0.2 & 1.2 & 0.2 & 1.3 & 0.3 & 1.2 & 0.4 \\
\hline
\end{tabular}

Table 2 Recycling Coefficient and Distribution Coefficient

\begin{tabular}{c|c|c|c|c|c}
\hline$\theta_{\mathrm{p}}$ & $\delta_{\mathrm{r}}$ & $\alpha_{\mathrm{d}}$ & $\beta_{\mathrm{e}}$ & $\varepsilon_{\mathrm{p}}$ & $\eta_{\mathrm{d}}$ \\
\hline 0.5 & 0.5 & 0.5 & 0.5 & 0.5 & 0.5 \\
\hline
\end{tabular}

Table 3 Unit Cost (Yuan/Part) and Carbon Emission (G/Part) under Three Conditions

\begin{tabular}{c|c|c|c|c|c}
\hline$w_{k}^{f}$ & $w_{k}^{e}$ & $u_{k}$ & $c_{k}^{f}$ & $c_{k}^{e}$ & $c_{k}$ \\
\hline 6000 & 6000 & 6000 & 50 & 50 & 50 \\
\hline
\end{tabular}


Table 4 Relevant Data (Part) in Consumption Area

\begin{tabular}{c|c|c|c|c|c|c}
\hline & 1 & 2 & 3 & 4 & 5 & 6 \\
\hline $\mathrm{d}_{\mathrm{k}}$ & 1500 & 2300 & 1500 & 1500 & 1300 & 1300 \\
\hline $\mathrm{q}_{\mathrm{k}}$ & 1000 & 2000 & 1000 & 1000 & 900 & 1000 \\
\hline
\end{tabular}

Table 5 Maximum Production and Processing Capacities of Various Facilities (Part)

\begin{tabular}{c|c|c|c|c|c|c}
\hline $\mathrm{c}_{\mathrm{s}}$ & $\mathrm{c}_{\mathrm{i}}$ & $\mathrm{c}_{\mathrm{l}}$ & $\mathrm{c}_{\mathrm{p}}$ & $\mathrm{c}_{\mathrm{r}}$ & $\mathrm{c}_{\mathrm{d}}$ & $\mathrm{C}_{\mathrm{e}}$ \\
\hline 8000 & 5000 & 5000 & 4000 & 5000 & 4000 & 4000 \\
\hline
\end{tabular}

Table 6 Maximum Transportation Capacities of Various Cars under Different Conditions (Thousand Parts)

\begin{tabular}{c|c|c|c|c|c|c|c|c}
\hline $\mathrm{c}_{\mathrm{ts}}$ & $\mathrm{c}_{\mathrm{ti}}$ & $\mathrm{c}_{\mathrm{tl}}$ & $\mathrm{c}_{\mathrm{tp}}$ & $\mathrm{c}_{\mathrm{tr}}$ & $\mathrm{c}_{\mathrm{td}}$ & $\mathrm{c}_{\mathrm{te}}$ & $\mathrm{c}_{\mathrm{tdi}}$ & $\mathrm{c}_{\mathrm{tei}}$ \\
\hline 6.5 & 5 & 5 & 4 & 2.5 & 2.5 & 2.5 & 2.5 & 2.5 \\
\hline
\end{tabular}

\section{Conclusions}

This paper establishes the optimization model of low-carbon closed-loop supply chain network with multiple objectives. Aiming at the model, a kind of improved genetic algorithm combined with $\varepsilon$ constraint method is raised to get the pareto optimal solution, which has been verified by algorithm case. The result of algorithm case shows that, the model can relatively reasonably solve the optimization problem of low-carbon closed-loop supply chain network with multiple objectives, and the used algorithm can efficiently get the pareto optimal solution. The article also discusses about the influence of utilization coefficient and partition coefficient of waste products to the range of pareto optimal solution, and analyze the reason why such influence is produced Finally, the article researches the variation range of optimal result when the product demand and product recycling demand of waste product in random. The article enriches the research content of low-carbon supply chain network and closed-loop supply chain network, is helpful for the enterprise to find the pareto optimal solution and control the range of pareto optimal solution by adjusting the coefficient, and also lay the foundation for establishing the low-carbon closed-loop supply chain network model with multiple products and periods.

\section{Reference}

[1] Xu L U. Third-party Logistics Construction of Oversea Location based on Cross-border Supply Chain Integration[J]. China Business \& Market, 2016.

[2] Cao S, Xu L. Research on the Overseas Warehouse Construction of Cross-Border E-Commerce[C]// the twelfth wuhan international conference on e-business. 2013.

[3] Zhang K, Huang L. Research on Cross-border E-commerce platform selection in China small \& medium-sized enterprises[C]// IEEE International Conference on Service Operations and Logistics, and Informatics. IEEE, 2015.

[4] Jiao Z L. Modes and Development Characteristics of China's Cross-border E-commerce Logistics[M]// Contemporary Logistics in China. Springer Berlin Heidelberg, 2016:211-232.

[5] Asosheh A, Shahidinejad H, Khodkari H. A Model of a Localized Cross-Border E-Commerce[J]. Ibusiness, 2012, 04(2):136-145. 